Check for updates

Cite this: Mater. Adv., 2021, 2,6428

Received 14th July 2021

Accepted 8th September 2021

DOI: $10.1039 / \mathrm{d} 1 \mathrm{ma00610}$

rsc.li/materials-advances

\section{Catalase-driven protein microtube motors with different exterior surfaces as ultrasmall biotools $\dagger$}

\author{
Mizuki Umebara, Natsuho Sugai, Kohei Murayama, Tomonao Sugawara, \\ Yushi Akashi, Yoshitsugu Morita, (D) Ryo Kato (D) and Teruyuki Komatsu (D)*
}

\begin{abstract}
This report describes synthesis of catalase-driven protein microtube (MT) motors with different exterior surfaces, highlighting their abilities of bacteria capture, reaction enhancement by self-stirring, and velocity control with light irradiation. Common precursor MTs with an internal wall of avidin (Avi MTs) were prepared using template synthesis with layer-by-layer (LbL) assembly in a track-etched polycarbonate (PC) membrane. Subsequently, (i) avidin-biotin complexation immobilized biotinylated catalase in the liberated MTs, and (ii) the outside wall was covered with lectins, enzymes, or Au nanoparticles (AuNPs). The designed MTs of four kinds (1.2 $\mu \mathrm{m}$ outer diameter, $24 \mu \mathrm{m}$ length) were selfpropelled in aqueous $\mathrm{H}_{2} \mathrm{O}_{2}$ solution powered by $\mathrm{O}_{2}$ bubble ejection from the terminal opening. The swimming (concanavalin A)-wrapped MTs captured Escherichia coli bacteria. The self-stirring motion of ( $\alpha$-glucosidase)-coated MTs promoted the hydrolysis reaction of $\alpha$-glucoside linkage. The similar (horseradish peroxidase)-covered MT motors used $\mathrm{H}_{2} \mathrm{O}_{2}$ as both a propulsion fuel and an oxidizing agent. Furthermore, the velocity of the swimming AuNP-bound MTs can be modulated by visible light irradiation. Photothermal heat generation by AuNPs increased the Cat enzyme activity. Notably, proteases digested the four MTs, demonstrating sufficient biodegradability. These results showed that the catalase-driven MT motors with different outer surfaces act as ultrasmall moving biotools.
\end{abstract}

\section{Introduction}

Swimming microtube (MT) motors with autonomous propulsion have been of particular scientific interest during the last decade ${ }^{1-12}$ because of their potential utility as pollutant removers, ${ }^{13,14}$ separation devices, ${ }^{15-18}$ and analytical sensors. ${ }^{19-21}$ Most synthetic MT motors possess an inner wall of platinum (Pt) thin film, where disproportionation reaction of $\mathrm{H}_{2} \mathrm{O}_{2}\left(2 \mathrm{H}_{2} \mathrm{O}_{2} \rightarrow\right.$ $2 \mathrm{H}_{2} \mathrm{O}+\mathrm{O}_{2}$ ) takes place. They are then powered by continuous jetting of $\mathrm{O}_{2}$ microbubbles from the open-end terminus. ${ }^{1,2,8,12,13,15-17,19-21}$ Such noble metal pipes were generally prepared using a rolling-up procedure with photolithography $y^{1,13,15}$ or electrochemical deposition in a porous membrane. ${ }^{2,8,16,17,19-21}$ An ultimate challenge for the MT motors is their implementation in life science applications such as ondemand drug carriers and as diagnostic microchip elements. However, the stiff MTs involving Pt walls are not biodegradable, which is the most important feature for biological and biomedical applications. Catalase (Cat.; $M_{\mathrm{w}}, 240 \mathrm{kDa}$; isoelectric point (pI), 5.5),

Department of Applied Chemistry, Faculty of Science and Engineering, Chuo University, 1-13-27 Kasuga, Bunkyo-ku, Tokyo 112-8551, Japan. E-mail: komatsu@kc.chuo-u.ac.jp; Fax: +81 33817 1910; Tel: +81 338171910 $\dagger$ Electronic supplementary information (ESI) available: Experimental details, Fig. S1-S5 and Videos S1-S4. See DOI: 10.1039/d1ma00610j a powerful enzyme capable of $\mathrm{H}_{2} \mathrm{O}_{2}$ dismutation, is an attractive alternative to Pt catalyst. Several pioneering achievements of Cat-powered MTs have been reported. ${ }^{22-26}$ Sanchez et al. fabricated Au-based MT motors in which Cat was immobilized by covalent bond. ${ }^{22}$ Wang et al. prepared polymer/Au-Cat MT motors that respond to various organic and inorganic toxins. ${ }^{23}$ Nonetheless, they still show poor biocompatibility. He et al. synthesized conical protein microrockets containing gelatin hydrogel with Cat. ${ }^{24}$ Free diffusion of $\mathrm{H}_{2} \mathrm{O}_{2}$ into the gel produced $\mathrm{O}_{2}$ bubbles to swim. The rockets, however, showed a limited lifetime for bubble generation. Furthermore, light-guided and driven MT motors have attracted considerable attention due to their potential in a variety of applications. ${ }^{5,27-31}$

Template-assisted synthesis using alternate layer-by-layer (LbL) assembly in a track-etched polycarbonate (PC) membrane is a beneficial procedure to create smart MTs comprising soft materials. ${ }^{32-41}$ Aqueous solutions of biopolymers such as polypeptides, DNAs, and proteins are filtered through the PC membrane and are deposited onto the pore walls. Subsequently, dissolution of the template in organic solvent provides uniform hollow cylinders. An important benefit of this strategy is that one can readily manipulate the interior wall by changing the final filtration material. Over the last decade, we demonstrated that various protein-based MTs and nanotubes (NTs) show unique functionalities such as molecular 
transport, ${ }^{37}$ virus trapping, ${ }^{38,39}$ bacteria killing, ${ }^{40}$ and molecular conversion. ${ }^{41}$ Furthermore, creation of a Cat wall in the capillary allowed the protein MTs to swim in aqueous $\mathrm{H}_{2} \mathrm{O}_{2}$ by jetting $\mathrm{O}_{2}$ bubbles from the terminal opening. ${ }^{26}$ The obtained hollow cylinders are digested properly by proteases, demonstrating a good biofriendly nature. To confer another task to the swimming protein MTs, the outer surface wall of the tubule must be used. It is nonetheless limited to change of the exterior surface in the initial step of template synthesis. Therefore, we first fabricated precursor MTs using LbL assembly in the porous PC membrane. Thereafter (i) the interior surface of the released tube was coated with Cat using avidin (Avi)-biotin complexation in aqueous medium, and (ii) the exterior surface was wrapped with desired materials using electrostatic interaction.

As described herein, we present the synthesis of protein MT motors having a Cat engine layer as an internal wall and different exterior surfaces $(1.2 \mu \mathrm{m}$ outer diameter (O.D.), $24 \mu \mathrm{m}$ tube length (T.L.)) (Fig. 1). Moreover, we emphasize their diverse functionalities with autonomous propulsion powered by $\mathrm{H}_{2} \mathrm{O}_{2}$ fuel. The swimming tubes covered with lectin bioreceptor can capture and release Escherichia coli (E. coli) bacteria. The enzyme-wrapped MT motors facilitated the catalytic reaction by their self-stirring motion. The velocity of the swimming MTs coated with gold nanoparticles (AuNPs) was modulated by light irradiation. The stratiform tubular walls were decomposed by proteases. Our findings constitute a new chemistry of soft protein MT motors that can become a platform of ultrasmall biotools for future biomedical applications.

\section{Results and discussion}

Synthesis of protein MTs with Cat interior surface (Cat MTs)

For our template synthesis using electrostatic LbL assembly in a microporous PC membrane, the first layer adhered on the
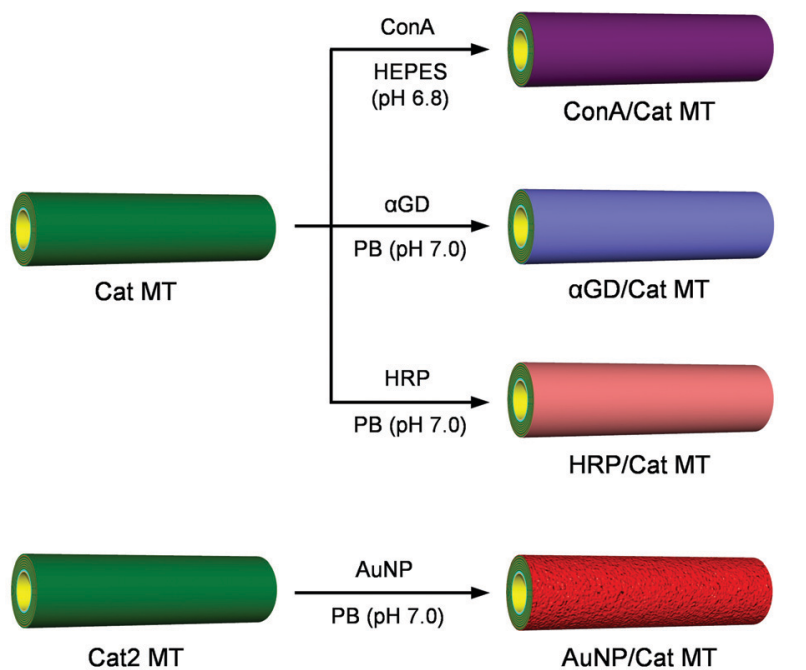

Fig. 1 Protein MT motors with a Cat engine layer as an internal wall and different exterior surfaces (concanavalin A, ConA; $\alpha$-glucosidase, $\alpha \mathrm{GD}$; horseradish peroxidase, HRP; and Au nanoparticle, AuNP). PLA/HSA/MNP (PLA/HSA) PLA/PLG/Avi/ bCat MT, Cat MT; (PLA/HSA) 7 PLA/PLG/Avi/bCat MT, Cat2 MT (poly(L-arginine), PLA; magnetite nanoparticle, MNP; and poly(L-glutamic acid, PLG). negatively charged pore wall must be positively charged material. $^{7,33,37}$ However, the lectin, enzymes, and AuNP that we would deploy on the exterior surface of the MT possess total charges of negative. In addition, the Cat layer deposited at the inner surface of the tube was denatured during the PC membrane dissolution in $\mathrm{DMF}^{26}$ Given the difficulty of preparing the designed MTs directly by template-assisted synthesis, we used a two-step procedure combining (i) electrostatic LbL deposition in the PC membrane and (ii) LbL coating in aqueous solution (Fig. 1 and 2). First, the human serum albumin (HSA)based precursor MTs containing an Avi $\left(M_{\mathrm{w}}, 68 \mathrm{kDa}\right.$; pI, 10.0-10.5) internal surface, PLA/HSA/MNP(PLA/HSA) ${ }_{5} \mathrm{PLA} / \mathrm{PLG} /$ Avi MTs (Avi MTs), were prepared in the PC membrane (Fig. 2A) [HSA as the major component, Avi as an innermost layer, magnetite NP (MNP) as the magnetic active layer, poly(L-arginine) (PLA) as a positively charged glue, and poly(L-glutamic acid) (PLG) as a negatively charged glue]. After etching the PC template in DMF solution, the released Avi MTs were freeze-dried, affording a lyophilized pale-yellow powder. Scanning electron microscopic (SEM) images showed the formation of uniform hollow cylinders with $1.14 \pm$ $0.04 \mu \mathrm{m}$ O.D. and $138 \pm 8 \mathrm{~nm}$ wall thickness (W.T.) (Fig. 2B). The maximum T.L. (approximately $24 \mu \mathrm{m}$ ) coincided well with the pore depth of the PC membrane used (Fig. 2C). We proposed a 16-layer model. Under an assumption that the sizes of PLA, PLG, HSA, and Avi are 8.7, 11.0, 8.0, and $6.0 \mathrm{~nm}$, respectively, from our earlier reported studies, ${ }^{26,37}$ the W.T. of the tube is estimated as $136 \mathrm{~nm}$. This value is close to the observed width of the dried MT (Fig. 2B).

Second, specific immobilization of Cat onto the internal Avi layer was conducted using Avi-biotin bonding in aqueous medium (Fig. 2D). Avi can bind four biotins with tremendously high affinity $\left(K>10^{15} \mathrm{M}^{-1}\right) .{ }^{42}$ The lyophilized powder of Avi MTs was suspended in phosphate-buffered saline (PBS) solution ( $\mathrm{pH}$ 7.4, $+150 \mathrm{mM} \mathrm{NaCl}$ ) by ultrasonication. Thereafter, biotinylated Cat [bCat; ten biotin arms were introduced on the surface lysine residues of Cat ${ }^{26}$ was added and the mixture was incubated for $3 \mathrm{~h}$. Before the experiments, we confirmed that the enzyme activity of Cat was unaltered by the introduction of biotin groups. ${ }^{26}$ To prevent nonspecific adhesion of bCat to the positively charged exterior surface of the tube, the $\mathrm{NaCl}$ concentration was increased to total $287 \mathrm{mM}$. Removing the unbound bCat by centrifugation conferred the PLA/HSA/MNP(PLA/HSA) ${ }_{5} \mathrm{PLA} / \mathrm{PLG} /$ Avi/bCat MTs (Cat MTs).

\section{ConA-covered Cat MTs (ConA/Cat MTs) and capture of E. coli}

First, we explored to capture bacteria using the bubblepropelled MT motors. Gram-negative bacteria such as Escherichia coli (E. coli) possess lipopolysaccharides (LPS) on their outer membranes. Concanavalin A (ConA; $M_{\mathrm{w}}, 104 \mathrm{kDa}$; pI, 4.5-5.5), a $\mathrm{Ca}^{2+} / \mathrm{Mn}^{2+}$ dependent lectin extracted from Canavalia ensiformis (Jack-bean), binds certain structures of various sugars and glycolipids, mainly terminal $\alpha$-D-mannosyl and $\alpha$-D-glucosyl residues. ${ }^{43}$ This lectin is known to recognize the specific terminal carbohydrates of LPS on E. coli surface and to form multiple valent binding. ${ }^{44}$ Wang et al. reported bacteria isolation using polymer-Pt MT engines. ${ }^{16}$ The ConA was 
(A)
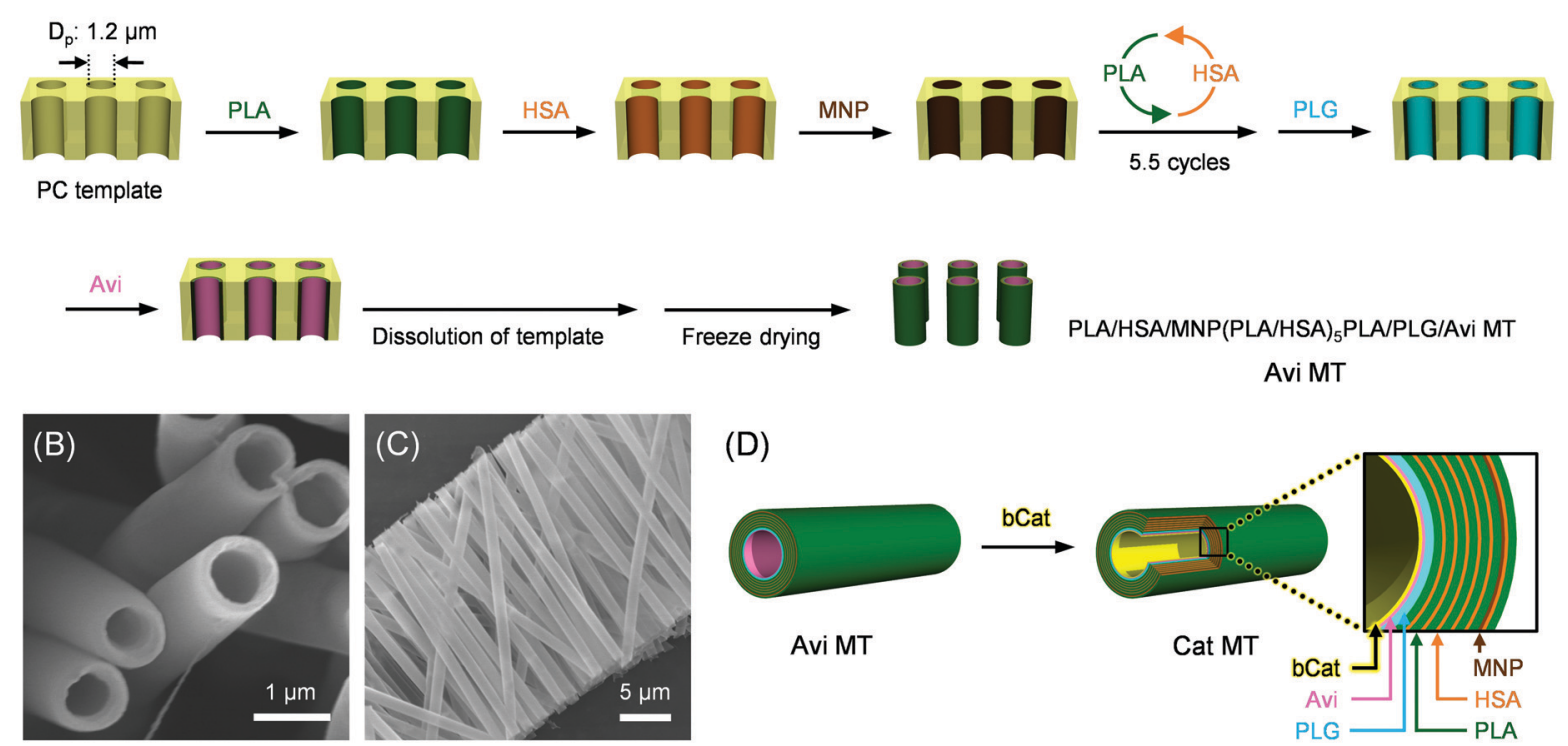

(D)

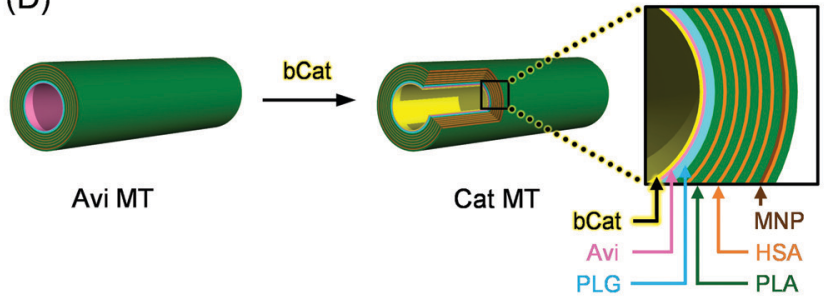

Fig. 2 (A) Synthetic scheme of a precursor PLA/HSA/MNP(PLA/HSA) 5 PLA/PLG/Avi MT (Avi MT) using LbL deposition in microporous PC membrane. ( $B$ and C) SEM images of Avi MTs. (D) Synthetic scheme of Cat MT by LbL coating of Avi MT with Cat in aqueous solution.

immobilized on the tube surface by gold-thiol chemistry. Quantitative evaluation, however, has never been done. For this study, we designed ConA-wrapped Cat MT motors that can capture E. coli while swimming in aqueous medium.

The Cat MTs were redispersed in 4-(2-hydroxyethyl)piprazineethanesulfonic acid (HEPES) solution (pH 6.8, $10 \mathrm{mM}$, including $\mathrm{Ca}^{2+}$ and $\mathrm{Mn}^{2+}$ ). Then, the negatively charged ConA was added to cover the exterior surface of the tubes. After incubation for $30 \mathrm{~min}$, the unbound ConA was removed by centrifugation, yielding ConA/PLA/HSA/MNP(PLA/HSA) $)_{5} \mathrm{PLA} / \mathrm{PLG} /$ Avi/bCat MTs (ConA/Cat MTs) (Fig. 1). Transmission electron microscopic (TEM) image of the air-dried sample revealed that the MTs swelled considerably in water. The W.T. became $283 \mathrm{~nm}$ (Fig. 3A). Because the dimensions of the proteins and MNP are constant, the polypeptide (PLA or PLG) layer thickness would be $25 \mathrm{~nm}$, which is greater than that observed in the freeze-dried sample of Avi MT (Fig. 2B). We ascertained the swelling ratio of the polypeptide layer as 2.5. This value was found in the range of normal polyelectrolytes $(1.2-4.0) .^{45,46}$

To ascertain the ConA coverage rate of the tube surface, we used fluorescent Cyanine 5.5 (Cy5.5)-labeled ConA (CyConA). The mixture of Cat MTs and CyConA was centrifuged to spin down the tubes. The fluorescence intensity of the supernatant was $39 \%$ of that observed for the identically treated CyConA solution without the tubes. This result implied that the number of adhered CyConA molecules per tube was approximately $2.3 \times$ $10^{8}$ and that the coverage rate of the MT surface with CyConA was $55 \%$. Moreover, similar tubules were prepared using fluorescein-labeled bCat (FCat) as an internal wall. Confocal laser scanning microscopy (CLSM) images of the CyConA/FCat MTs exhibited dual fluorescence emission (Fig. 3B). We inferred that (i) the homogeneous immobilization of bCat on the interior wall was achieved through strong avidin-biotin interaction and (ii) the CyConA molecules are adhered on the exterior wall of the tubules.

The ConA/Cat MTs were self-propelled in aqueous $\mathrm{H}_{2} \mathrm{O}_{2}$ solution by jetting $\mathrm{O}_{2}$ bubbles from the open end terminus with average velocity of $60 \pm 13 \mu \mathrm{m} \mathrm{s}^{-1}$ (2.5 body-lengths per s) (pH 6.8, 2 wt $\% \mathrm{H}_{2} \mathrm{O}_{2}, 0.1 \mathrm{wt} \%$ Triton X-100) (Fig. 3C, D and Video S1, ESI $\dagger$ ). The disproportionation of $\mathrm{H}_{2} \mathrm{O}_{2}$ was catalyzed by the innermost bCat engine layer. The continuous $\mathrm{O}_{2}$ bubble expulsion from one end is responsible for autonomous propulsion. After the first bubble exits one of the terminations, a one-way liquid flow of $\mathrm{H}_{2} \mathrm{O}_{2}$ fuel is generated in the onedimensional (1-D) channel. The swimming trajectories of the MTs mostly show a turning motion, which is attributed to slight differences of the tube's body symmetry and mouth shape. The structure was sufficiently robust to endure the continuous expulsion of $\mathrm{O}_{2}$ bubbles. Our MT motors retain their bubble ejection capability for $6 \mathrm{~h}$ at $2 \mathrm{wt} \% \mathrm{H}_{2} \mathrm{O}_{2}$. This stability contrasts with the fact that the conical protein microrockets with Cat lose their bubble propulsion ability within $10 \mathrm{~min} .^{24}$ One possible explanation is that the enzyme inhibitors such as hydroxyl radical are washed out from the channel of the tubes with water flow. We reasoned that the hollow cylinder structure is more preferred for biocatalytic $\mathrm{O}_{2}$ bubble propulsion for long period. The tubes including MNP layer can be collected easily by the magnet-field assistance. By bringing a neodymium (Nd)magnet (468 mT) close to the vessel, the swimming ConA/Cat MT was attracted by the magnet.

For bacteria capture experiments, we exploited a genetically engineered $E$. coli in which green fluorescent protein (GFP) is secreted (F-E. coli) (Fig. S1, ESI $\dagger$ ). Before the experiment, we ensured that the majority of F-E. coli can survive (remain viable and culturable) after exposure to the working solution containing $2 \mathrm{wt} \% \mathrm{H}_{2} \mathrm{O}_{2}$ fuel and $0.1 \mathrm{wt} \%$ Triton $\mathrm{X}-100$ used in our 

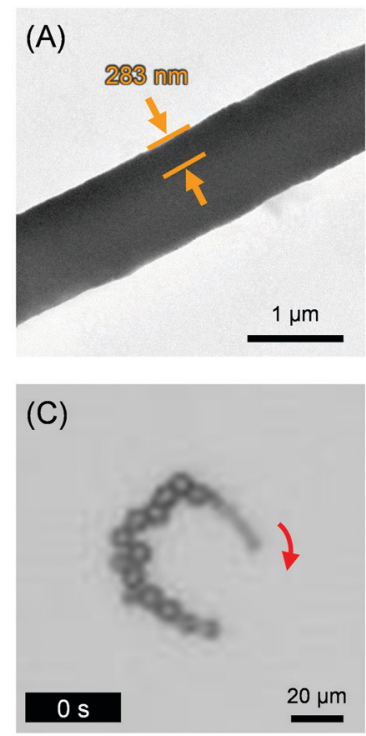

(F)
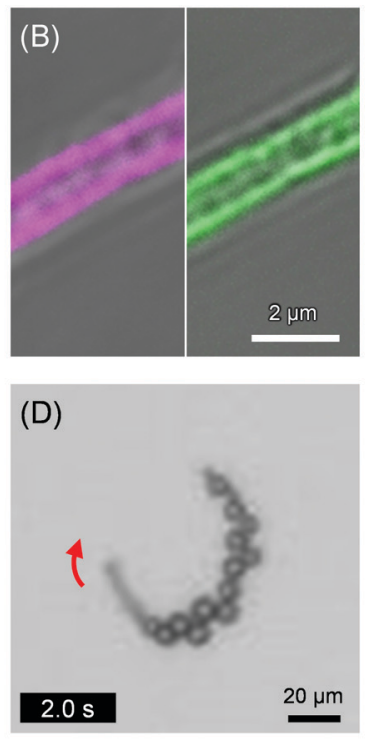

(E)

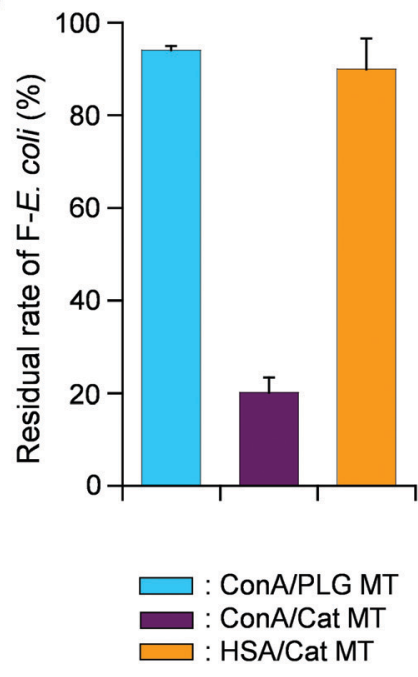

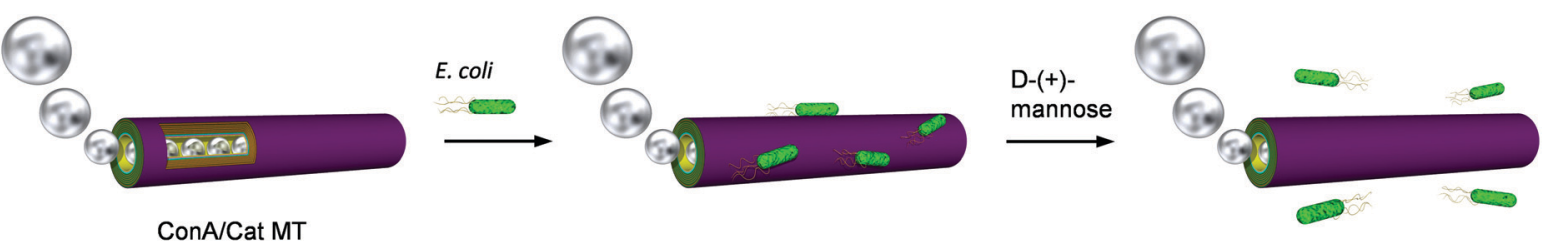

Fig. 3 (A) TEM images of ConA/Cat MT. (B) CLSM images of CyConA/FCat MT (left $-\lambda_{\text {ex }}, 633 \mathrm{~nm}$ for CyConA; right $-\lambda_{\text {ex }}, 488 \mathrm{~nm}$ for FCat). (C and D) Snapshots taken from Video $\mathrm{S} 1$ (ESI $\dagger$ ) of microscopic observations of self-propelled ConA/Cat MT by jetting $\mathrm{O}_{2}$ bubbles in $\mathrm{HEPES}$ solution (pH $6.8,2$ wt\% $\mathrm{H}_{2} \mathrm{O}_{2}, 0.1$ wt\% Triton X-100) at $25^{\circ} \mathrm{C}$ under bright field mode. (E) Residual rate of $E$. coli after incubation with self-propelled ConA/Cat MTs. Results were ascertained using the fluorescence spectral intensity of GFP in the remaining F-E. coli. (F) Schematic illustration of catch and release of $E$. coli on the exterior surface of a bubble-propelled ConA/Cat MT.

experiments for $15 \mathrm{~min}$ (ESI $\dagger$ ). The Con A-LPS binding allows the tube to capture F-E. coli regardless of their bacterial viability or calturability. To the HEPES dispersion of self-propelled ConA/Cat MTs ( $\mathrm{pH} 6.8,2$ wt\% $\mathrm{H}_{2} \mathrm{O}_{2}, 0.1$ wt\% Triton X-100), the F-E. coli suspension was added. The ConA/Cat MTs were swimming in the bacteria suspension by spouting out of $\mathrm{O}_{2}$ bubbles. The mixture was incubated for 15 min under dark conditions at $25{ }^{\circ} \mathrm{C}$. Later, the tubules were collected using a Nd-magnet. The supernatant was centrifuged to precipitate the unbound F-E. coli, which was redispersed in HEPES solution. The fluorescence intensity of the dispersion was only $20 \%$ of that observed for the identically treated F-E. coli without the tubes (Fig. 3E). The $80 \%$ removal of F-E. coli from the sample solution was achieved by single treatment with the swimming MTs (Fig. 3F). The average number of F-E. coli adhered on the exterior surface was calculated as 3.9 per tube. Additional experiments were conducted with control MTs. Incubation with the non-swimming ConA/PLG MTs, which were always sinking at the bottom, showed 94\% fluorescence intensity relative to the control value (Fig. 3E). Furthermore, the HSA/Cat MTs, which have no ConA wall, exhibited $90 \%$ of the control. Our results demonstrated that self-propelled ConA/MT motors capture F-E. coli efficiently and showed that the swimming motion plays an important role in accelerating the collision frequency to bind the bacteria.
Once F-E. coli attached to the swimming ConA/Cat MT, it became tightly bound onto the cylinder and never was shaken off. To release the captured F-E. coli, mannose was added. It is noteworthy that efficient unloading of bacteria occurred by addition of $\mathrm{D}^{-}(+)$-mannose to the tube dispersion. Dissociation of F-E. coli-ConA complex caused the elevation of fluorescence intensity to $78 \%$ of that for the total captured F-E. coli. We concluded that (i) the specific binding between the ConA surface of the tube and LPS surface of F-E. coli is solely responsible for the capture. Also, we concluded that (ii) autonomous propulsion is crucially important to increase the molecular contact frequency and to promote bacteria catching. The selfpropelled ConA/Cat MTs can act as ultrasmall removers and separators for $E$. coli.

\section{Enzyme-covered Cat MTs and self-stirring biocatalyst}

The next challenge in using bubble-propelled MT is to create self-stirring catalysts. Immobilization of an enzyme onto the outer surface would allow the MT motors to have biocatalytic activity. The self-propulsive motion is anticipated to facilitate the reaction. The $\alpha$-glucosidase from Saccharomyces cerevisiae $\left(\alpha \mathrm{GD} ; M_{\mathrm{w}}, 68.5 \mathrm{kDa} ; \mathrm{pI}, 4.0-5.5\right)$ is a typical exo-type carbohydrase to cleave the $\alpha(1 \rightarrow 4)$ bond at the non-reducing terminal end of the substrate to release an $\alpha$-D-glucose 
(eqn (1)). ${ }^{47}$

$$
\text { RO- } \alpha \text {-D-glucose }+\mathrm{H}_{2} \mathrm{O} \stackrel{\alpha \mathrm{GD}}{\longrightarrow} \mathrm{ROH}+\alpha \text {-D-glucose }
$$

The $\alpha$ GD was added to the PB dispersion ( $\mathrm{pH}$ 7.0) of Cat MTs and the mixture was incubated for $30 \mathrm{~min}$. The MTs were collected using a Nd-magnet and the supernatant was discarded, yielding $\alpha \mathrm{GD} / \mathrm{PLA} / \mathrm{HSA} / \mathrm{MNP}(\mathrm{PLA} / \mathrm{HSA})_{5} \mathrm{PLA} / \mathrm{PLG} /$ Avi/bCat MTs $(\alpha \mathrm{GD} /$ Cat MTs) (Fig. 1). TEM image of the air-dried sample revealed that the MTs swelled in water. The W.T. of the MT was $283 \mathrm{~nm}$ (Fig. 4A), which is identical to that of ConA/Cat MT. The $\alpha \mathrm{GD}$ coverage rate of the tube surface was determined using fluorescein-labeled $\alpha \mathrm{GD}$ (F $\alpha \mathrm{GD})$. By attaching a Nd-magnet to the vessel, the F $\alpha \mathrm{GD} / \mathrm{Cat}$ MTs were attracted at the bottom. The supernatant fluorescence spectrum was measured to ascertain the concentration of unbound $\mathrm{F} \alpha \mathrm{GD}$. The fluorescence intensity declined to $30 \%$ of that for the identically treated F $\alpha \mathrm{GD}$ solution without the tubes. This result signifies that the number of adhered F $\alpha$ GD molecules per tube was approximately $1.9 \times 10^{6}$ and that the coverage rate of the MT surface with F $\alpha$ GD was $30 \%$. A CLSM image of the $\mathrm{F} \alpha \mathrm{GD} / \mathrm{Cat}$ MTs showed wrapping of the outside wall of the cylinder by F $\alpha$ GD (Fig. 4B). The $\alpha$ GD/Cat MTs were also self-propelled in aqueous $\mathrm{H}_{2} \mathrm{O}_{2}$ solution by jetting $\mathrm{O}_{2}$ bubbles from the open end with average velocity of $68 \pm$ $15 \mu \mathrm{m} \mathrm{s}^{-1}$ (2.8 body-lengths per s) (pH 7.0, 2 wt\% $\mathrm{H}_{2} \mathrm{O}_{2}$, $0.1 \mathrm{wt} \%$ Triton X-100) (Fig. 4C, D and Video S2, ESI $\dagger$ ). The swimming behavior with a turning motion resembled that of ConA/Cat MT.

As a fluorogenic substrate, we used 4-methylumbelliferyl- $\alpha$ D-glucopyranoside (MUGlc) (Fig. 4E). The reaction product, 4-methylumbelliferone (MU), is a coumarin compound showing fluorescence at $447 \mathrm{~nm}$. Upon addition of MUGlc to the PB solution ( $\mathrm{pH} 7.0,2 \mathrm{wt} \% \mathrm{H}_{2} \mathrm{O}_{2}, 0.1 \mathrm{wt} \%$ Triton X-100) of free $\alpha \mathrm{GD}$, fluorescence $\left(\lambda_{\mathrm{em}}, 447 \mathrm{~nm}\right)$ and $\mathrm{UV}$ absorption $(\lambda, 370 \mathrm{~nm})$ increased gradually, demonstrating the generation of $\mathrm{MU}$ (Fig. 4F). The MU concentration reached $50 \mu \mathrm{M}$ after $15 \mathrm{~min}$. Later, identical experiments were conducted using $\alpha \mathrm{GD} / \mathrm{Cat} \mathrm{MT}$ motors. After adding MUGlc to the PB dispersion of swimming tubes ( $\mathrm{pH} 7.0,2 \mathrm{wt} \% \mathrm{H}_{2} \mathrm{O}_{2}, 0.1 \mathrm{wt} \%$ Triton X-100), we observed a fluorescence increase at $447 \mathrm{~nm}$, from which the MU concentration was calculated. It reached maximum $30 \mu \mathrm{M}$ after $50 \mathrm{~min}$ (Fig. 4F), representing that the enzyme activity of the swimming $\alpha \mathrm{GD} / \mathrm{Cat}$ MTs was lower than that of the free $\alpha \mathrm{GD}$. This restricted activity might be attributable to the sparse distribution of the $\alpha \mathrm{GD}$ molecules on the tube surface with statistic geometries. We presumed a four-part model of $\alpha \mathrm{GD}$ in which an active site locates in one of the four parts (Fig. S2, ESI $\dagger$ ). The probability of the active site facing the aqueous solution is half $(50 \%)$ or three-fourths $(75 \%)$, with an average of $63 \%$. This presumably engenders lower enzyme activity. The result is consistent with our earlier reported data for the protein MTs and NTs with an $\alpha \mathrm{GD}$ surface. ${ }^{12,48}$ The same reaction using non-swimming $\alpha$ GD-covered $\alpha \mathrm{GD} / \mathrm{PLA} / \mathrm{HSA} / \mathrm{MNP}(\mathrm{PLA} / \mathrm{HSA})_{5} \mathrm{PLA} / \mathrm{PLG}$ MTs $(\alpha \mathrm{GD} /$ PLG MTs) showed considerably low activity ("Non-stirring" in Fig. 4F). This low activity was expected, but surprisingly, stirring
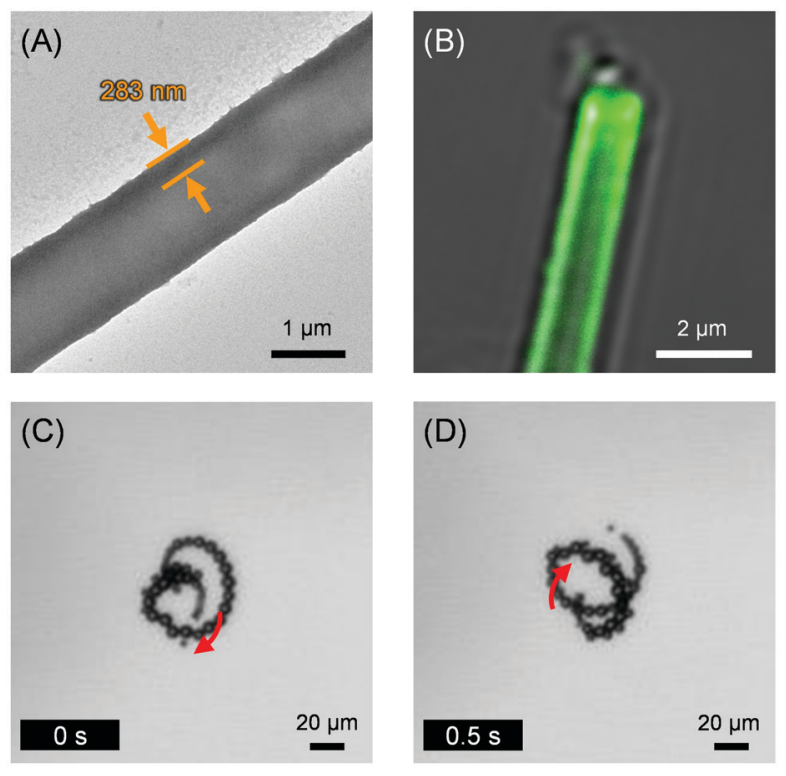

(E)

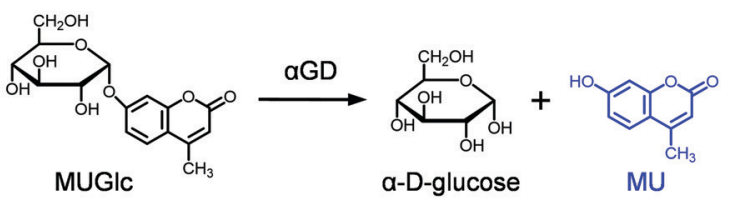

(F)

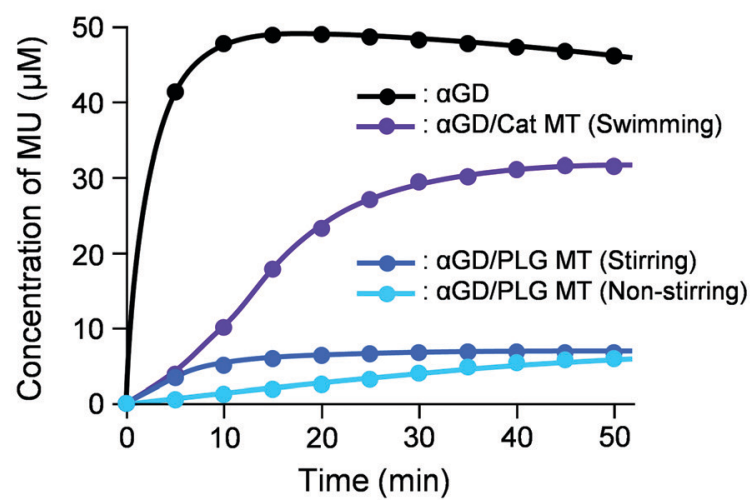

Fig. 4 (A) TEM image of $\alpha G D / C$ at MT. (B) CLSM images of F $\alpha$ GD/Cat MT $\left(\lambda_{\text {ex }}, 488 \mathrm{~nm}\right.$ ). (C and D) Snapshots taken from Video S2 (ESI $\dagger$ ) of microscopic observations of self-propelled $\alpha \mathrm{GD} / \mathrm{Cat}$ MT by jetting $\mathrm{O}_{2}$ bubbles in PB solution ( $\mathrm{pH} 7.0,2 \mathrm{wt} \% \mathrm{H}_{2} \mathrm{O}_{2}, 0.1$ wt\% Triton X-100) at $25{ }^{\circ} \mathrm{C}$ under bright field mode. (E) Hydrolysis reaction of fluorogenic substrate MUGlc to generate $\mathrm{MU}$. (F) Time course of $\mathrm{MU}$ concentration in the PB solution ( $\mathrm{pH} 7.0,2 \mathrm{wt} \% \mathrm{H}_{2} \mathrm{O}_{2}, 0.1 \mathrm{wt} \%$ Triton X-100) of MUGlc with swimming $\alpha \mathrm{GD} /$ Cat MTs or non-swimming $\alpha \mathrm{GD} / \mathrm{PLG}$ MTs at $25^{\circ} \mathrm{C}$.

of the reaction mixture of MUGlc and $\alpha \mathrm{GD} / \mathrm{PLG}$ MTs using a magnetic stirrer $(300 \mathrm{rpm})$ did not promote the reaction ("Stirring" in Fig. 4F). It is noteworthy that the product MU concentration was equivalent to that with the non-stirring $\alpha \mathrm{GD} /$ PLG MTs after $50 \mathrm{~min}$. Two causes can be reasonably inferred. The $\alpha \mathrm{GD} / \mathrm{PLG}$ MTs including MNP layer were absorbed tightly onto the magnetic stirrer bar. Thereby, (i) collision between $\alpha \mathrm{GD}$ and substrate occurred less frequently, and (ii) $\alpha \mathrm{GD}$ immobilized 
on the tube was denatured momentarily by rubbing with highspeed mechanical rotation.

Next, horseradish peroxidase (HRP; $M_{\mathrm{w}}, 40.2 \mathrm{kDa}$; pI, 3.09.0) was used as a surface enzyme of the MT motor. Actually, HRP, a heme-containing enzyme, catalyzes the oxidation of widely various organic substrates using $\mathrm{H}_{2} \mathrm{O}_{2}$. ${ }^{49}$ The high turnover rate of this protein allows generation of a strong signal in a short time. The characteristic color of the products can be observed readily using simple spectrophotometry. For that reason, HRP is ideal for many applications and is commonly used in enzyme-linked immunosorbent assay (ELISA) and immunohistochemistry. Because our working solution of the Cat MT motors contains $2 \mathrm{wt} \% \mathrm{H}_{2} \mathrm{O}_{2}$, the synthesized tubules are expected to use $\mathrm{H}_{2} \mathrm{O}_{2}$ as a propulsion fuel in the hollow cylinder and also as an oxidizing agent on the outside enzyme surface.

The PB solution of HRP was added to wrap the exterior surface of Cat MTs. After incubation for $30 \mathrm{~min}$, the MTs were collected using a Nd-magnet. The supernatant was removed, yielding HRP/PLA/HSA/MNP(PLA/HSA) ${ }_{5} \mathrm{PLA} / \mathrm{PLG} /$ Avi/bCat MTs (HRP/Cat MTs) (Fig. 1). The TEM image of the air-dried sample exhibited $281 \mathrm{~nm}$ wall thickness (Fig. 5A), which is similar to values found for ConA/Cat MT and $\alpha \mathrm{GD} / \mathrm{Cat} \mathrm{MT}$ in a swelled state. To ascertain the surface covering rate with HRP, we exploited Cy5.5-labeled HRP (CyHRP). From the mixture of Cat MTs and CyHRP, the CyHRP/Cat MTs were excluded using a Nd-magnet. Then the fluorescence of the supernatant was measured. The fluorescence intensity declined to $34 \%$ of that for the identically treated CyHRP solution without the tubes. The number of adhered CyHRP molecules per tube was ascertained as approximately $4.8 \times 10^{6}$. The coverage rate of the MT surface with CyHRP was 59\%. The zeta potentials of the Avi MT and Cat MT were observed respectively at $48.0 \mathrm{mV}$ and $52.0 \mathrm{mV}$. These results manifested that the exterior surfaces of the cylinders indeed consist of positively charged PLA layer. In marked contrast, the zeta potential of HRP/Cat MT was found to be $-10.0 \mathrm{mV}$, implying that the wrapping by HRP inverted the surface charge of the tube to negative. Although HRP used for this study was a mixture of isoforms with wide range of pI, 3.0-9.0, the acidic components are likely to bind the tube by electrostatic interaction. The obtained HRP/Cat MTs swam smoothly in $2 \mathrm{wt} \%$ aqueous $\mathrm{H}_{2} \mathrm{O}_{2}$ medium with a turning motion (Fig. 5B and Video S3, ESI $\dagger$ ). The swimming speed was $66 \pm 13 \mu \mathrm{m} \mathrm{s}^{-1}$ (2.8 body-lengths per $\left.\mathrm{s}\right)$. The difference in exterior surface (ConA, $\alpha$ GD, or HRP) did not affect the catalytic performance of the inside wall of the MT motor.

Numerous substrates for HRP have been developed and commercialized. As the first chromogenic substrate, we choose $o$-phenylenediamine (OPD, Fig. 5C), which is used extensively in HRP-mediated ELISA. ${ }^{50}$ The soluble product is an orangebrown 2,3-diaminophenazine (DAP) with strong absorption at $417 \mathrm{~nm}$. Upon addition of OPD to the swimming HRP/Cat MTs dispersion ( $\mathrm{pH} 7.0,2 \mathrm{wt} \% \mathrm{H}_{2} \mathrm{O}_{2}, 0.1 \mathrm{wt} \%$ Triton $\left.\mathrm{X}-100\right)$, the color changed immediately to yellow. The $\mathrm{H}_{2} \mathrm{O}_{2}$ in the medium was consumed as both fuel for autonomous propulsion and
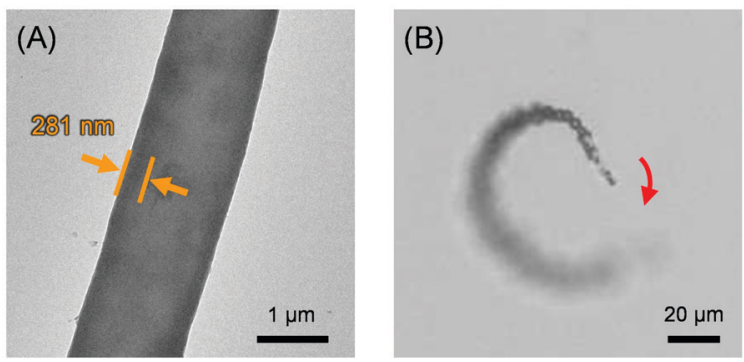

(C)
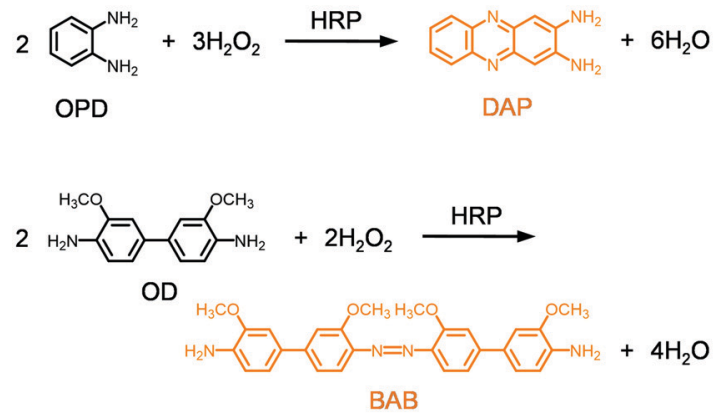

(D)

(E)

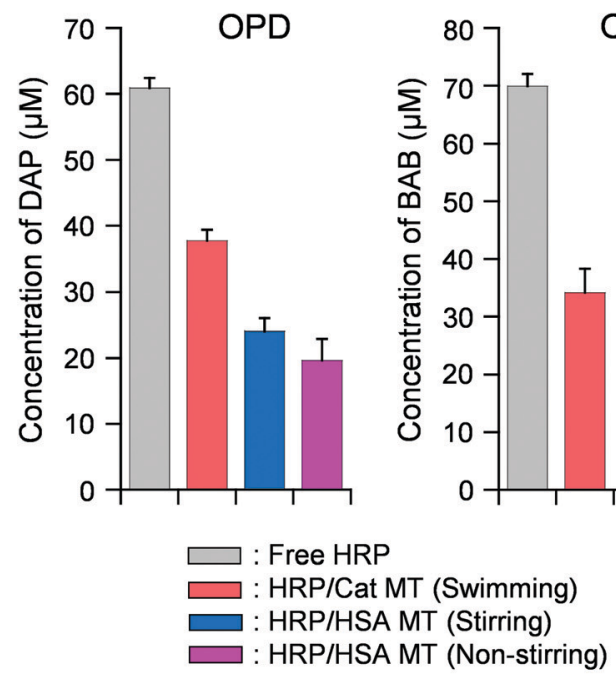

Fig. 5 (A) TEM image of HRP/Cat MT. (B) Snapshot taken from Video S3 $(E S I \dagger)$ of microscopic observations of self-propelled HRP/Cat MT by jetting $\mathrm{O}_{2}$ bubbles in $\mathrm{PB}$ solution $\left(\mathrm{pH} 7.0,2\right.$ wt $\% \mathrm{H}_{2} \mathrm{O}_{2}, 0.1$ wt\% Triton X-100) at $25{ }^{\circ} \mathrm{C}$ under bright field mode. (C) Oxidation reactions of chromogenic substrates, OPD and OD. (D) Product DAP concentrations in the PB solution ( $\mathrm{pH} 7.0,2$ wt\% $\mathrm{H}_{2} \mathrm{O}_{2}, 0.1$ wt\% Triton X-100) of OPD with swimming HRP/Cat MTs and non-swimming HRP/HSA MTs at $25{ }^{\circ} \mathrm{C}$. (E) Product BAB concentrations in the PB solution $\left(\mathrm{pH} 7.0,2 \mathrm{wt} \% \mathrm{H}_{2} \mathrm{O}_{2}\right.$, 0.1 wt\% Triton X-100) of OD with swimming HRP/Cat MTs and nonswimming HRP/HSA MTs at $25^{\circ} \mathrm{C}$.

oxidizing agent. After $20 \mathrm{~min}$, the tubules were collected using a Nd-magnet. The visible absorption spectrum of the supernatant was measured. The absorption intensity at $417 \mathrm{~nm}$ suggested that the DAP concentration reached $38 \pm 2 \mu \mathrm{M}$, which is $62 \%$ of the value observed for the free HRP solution in an identical setup (Fig. 5D). This restriction percentage is exactly the same 
as that of the carbohydrase reaction with $\alpha \mathrm{GD} / \mathrm{Cat}$ MT motors described above. Furthermore, we conducted similar experiments using non-swimming HRP-covered HRP/PLA/HSA/MNP(PLA/ HSA) $)_{5}$ PLA/PLG/Avi/bHSA MTs (HRP/HSA MTs) with and without stirring using a magnetic stirrer bar (300 rpm). The concentration of product DAP after $20 \mathrm{~min}$ in the non-stirring condition was $20 \pm 3 \mu \mathrm{M}$ (Fig. 5D). This somewhat higher than expected value might have arisen from (i) high catalytic activity of HRP and (ii) the technical limits to prevent the unavoidable partial mixing of the heterogeneous solution occurred by adding the substrate solution and by collecting the supernatant. Again, it is remarkable that the stirring of the mixture using a magnetic stirrer did not facilitate the reaction. Similar DAP concentration was observed to that of non-stirring condition (Fig. 5D).

Second, o-dianisidine (OD, Fig. 5C), which is also typical substrate for HRP, was examined. ${ }^{51}$ The stable product is a brown bisazobiphenyl (BAB), which is regarded as produced by self-coupling of two quinonediimines at neutral $\mathrm{pH}$. The BAB shows strong absorption at $455 \mathrm{~nm}$. The product concentration in the HRP/Cat MT motor dispersion was $49 \%$ of that for the free HRP solution (Fig. 5E). In the case of non-swimming HRP/ HSA MTs, the forced stirring did not improve the reaction compared to that of the swimming MTs. The trend closely resembled the results observed for OPD. All data of HRP/Cat MT motors supported strongly our mechanism proposed in the swimming $\alpha \mathrm{GD} /$ Cat MTs. Overall, these findings manifested that the enzyme/Cat MT motors act as ultrasmall biocatalyst with self-stirring motion to promote the enzyme reaction. In this study, self-stirring motion can be defined as the MT's unique swimming movement, which causes sufficient collisions between surface enzymes and substrates without denaturing the enzymes. The motors are expected to be useful in a very narrow channel in a microfluidic device and a very small aqueous droplet, where a magnetic stirrer cannot be used.

\section{AuNP-covered Cat MTs (AuNP/Cat MTs) and velocity control with light irradiation}

Not only lectin, enzymes, but also metal nanoparticles are able to functionalize the Cat MT motors. AuNPs possess photothermal heating ability. For example, they are developed as suitable agents for thermal destruction of cancer cells. ${ }^{52}$ The photothermal property of AuNP rely on its ability to convert the absorbed light into heat. The red color of AuNPs is attributed to a localized surface plasmon resonance (LSPR) in which the conduction electrons on the surface of the NP oscillate in resonance with incident light. $\mathrm{He}$ et al. reported the ultrasound-driven AuNP functionalized NTs for photochemical perforation of a cancer cell. ${ }^{31}$ The Cat demonstrates maximum activity at $37{ }^{\circ} \mathrm{C}$, which is the optimal temperature of the enzyme. ${ }^{53}$ We previously reported that the velocity of Cat MT motors was regulated by varying the enzyme activity with $\mathrm{pH}$ and temperature of bulk aqueous solution. ${ }^{26}$ If one can enwrap the exterior surface of Cat MTs with AuNPs, light irradiation engenders heat generation to increase the enzyme activity of Cat, which might then accelerate the swimming tubes.
The citrate-reduced AuNPs with $40 \pm 3 \mathrm{~nm}$ diameter were synthesized according to our earlier reported procedure. ${ }^{54}$ The aqueous AuNP solution showed a characteristic SPR band at $530 \mathrm{~nm}$ (Fig. S3, ESI $\dagger$ ), which is well consistent with data reported elsewhere. ${ }^{55}$ The zeta potential of the AuNP was $-34.0 \mathrm{mV}$, implying the surface charge is sufficiently negative. The (PLA/HSA) ${ }_{7}$ PLA/PLG/Avi/bCat MTs (Cat2 MTs) without MNP layer were prepared from (PLA/HSA) ${ }_{7} \mathrm{PLA} / \mathrm{PLG} /$ Avi MTs (Fig. S4, ESI $\dagger$ ) and used as parent tubes. The MNP layer was excluded to prevent unfavorable adsorption of the generated heat. The Cat2 MTs were suspended in aqueous AuNP solution to wrap the outside surface of the tube. After incubation for $30 \mathrm{~min}$, the unbound AuNP was removed by centrifugation,

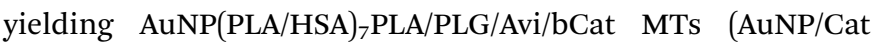
MTs) (Fig. 1). From the absorption spectrum of the supernatant including unbound free AuNP (Fig. S3, ESI $\dagger$ ) the average numbers of the AuNPs immobilized onto the one tube were estimated as $2.0 \times 10^{4}$. The coverage rate of the MT surface with AuNPs was calculated as $30 \%$. The TEM image of the AuNP/Cat MT showed homogeneous distribution of AuNPs on the cylindrical wall (Fig. 6A). Careful inspection of the TEM picture revealed that the wrapping rate of the tube surface with the particles was $33 \%$ (Fig. 6B), which is almost equivalent to the value from the UV-vis absorption measurement. The density of the AuNP distribution in Fig. 6B appears to be higher than $33 \%$, probably because the picture shows all particles absorbed on both-side of the flattened tube on the TEM grid. The AuNP/ Cat MTs were self-propelled in PB solution with $\mathrm{H}_{2} \mathrm{O}_{2}(\mathrm{pH}$ 7.0, 2 wt $\% \mathrm{H}_{2} \mathrm{O}_{2}, 0.1 \mathrm{wt} \%$ Triton X-100) by jetting $\mathrm{O}_{2}$ microbubbles (Video S4A, ESI $\dagger$ ). The average velocity of $53 \pm 12 \mu \mathrm{m} \mathrm{s}^{-1}$ (2.2 body-lengths per s) was markedly less than that of parent Cat2 MTs ( $66 \pm 11 \mu \mathrm{m} \mathrm{s}^{-1}, 2.8$ body-lengths per s). Wrapping of the surface with heavy AuNPs increased the tube weight and slowed it down.

Movement of the AuNP/Cat MT was observed under bright field mode with light irradiation using a $\mathrm{Hg}$ lamp through a fluorescence mirror unit (Ex, 530-550 nm/Em, $575 \mathrm{~nm}$ ) at room temperature. The light intensity was modulated using ND filters (0-193 $\mathrm{mW} \mathrm{cm}^{-2}$ ). As expected, the AuNP/Cat MTs swim much faster under light irradiation: $92 \pm 11 \mu \mathrm{m} \mathrm{s}^{-1}$ (3.8 bodylengths per s) at $139 \mathrm{~mW} \mathrm{~cm}^{-2}$ (Fig. 6C, D and Video S4B, ESI $\dagger$ ). Photothermal property of the AuNPs on the exterior surface of the MTs induced heat generation and raised the hierarchical wall temperature. Thereby, the increased enzyme activity enhanced the swimming speed of the tube. Indeed, the mobility of the AuNP/Cat MTs was changed in response to the optical intensity. A maximum peak appeared at $139 \mathrm{~mW} \mathrm{~cm}^{-2}$, where the wall temperature might reach the optimum temperature of the Cat (Fig. 6C and D). ${ }^{53}$ Further strong irradiation at $193 \mathrm{~mW} \mathrm{~cm}{ }^{-2}$ reduced the velocity, implying that the wall became warmer than the optimum temperature. In striking contrast, the swimming speed of the Cat2 MT motor without AuNP was unaffected by optical intensity. We confirmed that the bulk aqueous medium temperature was unaltered under light irradiation; it remained constant at $26.4-27.6{ }^{\circ} \mathrm{C}$ (line chart in Fig. 6D). These acceleration and deceleration by visible light were fully reversible. The Cat 

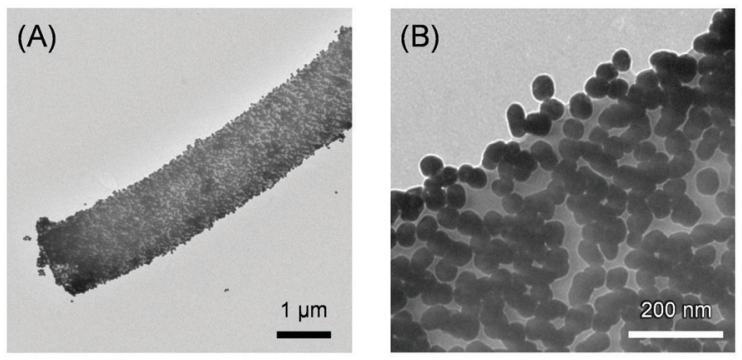

(C)

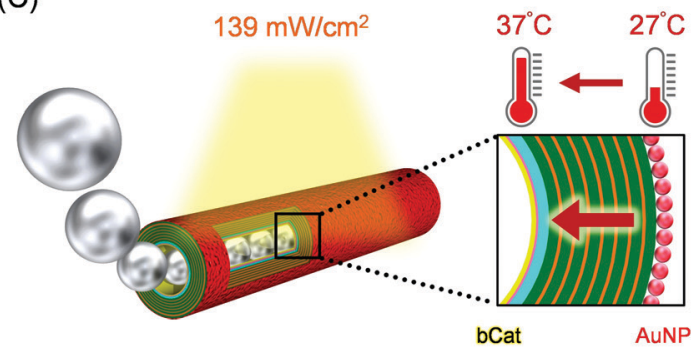

(D)

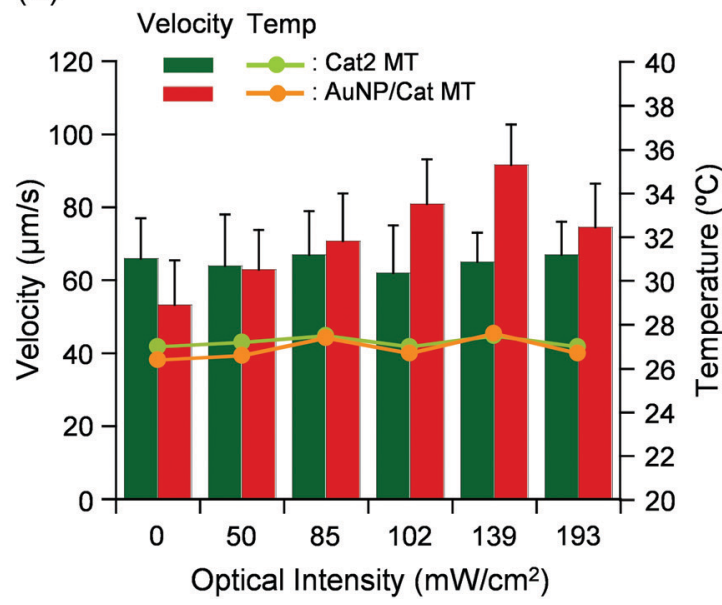

Fig. 6 (A and B) TEM images of AuNP/Cat MT. (C) Schematic illustration of temperature increase in self-propelled AuNP/Cat MT by light irradiation. (D) Influence of optical intensity on the average velocity of self-propelled AuNP/Cat MTs and the parent Cat2 MTs (pH 7.0, 2 wt\% $\mathrm{H}_{2} \mathrm{O}_{2}, 0.1 \mathrm{wt} \%$ Triton $\mathrm{X}-100$ ) and on the temperature of the bulk aqueous solution.

engine layer and AuNP photothermal layer are robustly immobilized respectively on the interior and exterior walls. We inferred from these findings that the AuNP/Cat MT motor's velocity can be tuned by the regulation of enzyme activity with photothermal heat generation of the outside AuNPs mantle.

\section{Biodegradability}

Biodegradability is the most important feature for biological and biomedical applications. The cylindrical shapes of ConA/ Cat MTs, $\alpha$ GD/Cat MTs, HRP/Cat MTs, and AuNP/Cat MTs became short and slender in the aqueous solution of Pronase, a cocktail of several proteases, within $2 \mathrm{~h}$ at $37{ }^{\circ} \mathrm{C}$ (Fig. S5, ESI $\dagger$ ). It can be inferred that proteases digested the protein and polypeptide layers in the tubular walls. The remaining aggregates of MNPs or AuNPs were dispersed immediately by sonication. The MNPs and AuNPs show no cytotoxicity to living cells. ${ }^{56,57}$ We inferred that the four Cat MTs having different exterior surfaces possess sufficient biodegradability.

\section{Conclusions}

Protein MT motors with Cat engine layer on the interior wall and different functional material layers on the exterior wall were synthesized using a combination of LbL build-up assemblies in PC membrane and aqueous bulk solution. The MTs are selfpropelled catalytically in aqueous $\mathrm{H}_{2} \mathrm{O}_{2}$ medium by ejection of $\mathrm{O}_{2}$ bubbles from the open-end terminus. The swimming tubes demonstrated interesting biofunctionalities with self-propulsive motion. The E. coli was captured specifically on the ConA outer surface of the tubules, providing green-emitting MTs. The lectinLPS bonding is sufficiently strong to hold the bacteria on the swimming tube. Moreover, the $\alpha \mathrm{GD}$-wrapped MTs act as a selfstirring biocatalyst that promotes the enzyme reaction by continuous movement. This enhancement was observed similarly on HRP/Cat MT motors. Phototermal heating of AuNP outside surface of the capillary enables control of the tube's velocity by visible light irradiation. All MTs were decomposed by protease, signifying biodegradability. It is apparently possible to immobilize other proteins or antibodies on the exterior surface and to create diverse MTs that can capture and transport targeted drugs, viruses, and pathogenic bacteria. Although the relatively high $\mathrm{H}_{2} \mathrm{O}_{2}$ concentration limits the scope of the experimentation and implementation design, ${ }^{5,58-60}$ the tailormade protein MT motors with biofriendly nature are anticipated as promising biotools used in various biological and biomedical applications.

\section{Materials and methods}

\section{Materials and apparatus}

Poly(L-arginine) hydrochloride (PLA; $\left.M_{\mathrm{w}},>70000\right)$; poly(Lglutamic acid) sodium salt (PLG; $\left.M_{\mathrm{w}}, 50000-100000\right)$, horseradish peroxidase (HRP), 4-methylumbelliferyl- $\alpha$-D-glucopyranoside (MUGlc), o-phenylenediamine (OPD), and o-dianisidine dihydrochloride (OD) were purchased from Sigma-Aldrich Co. LLC. Catalase from bovine liver (Cat), $\alpha$-glucosidase ( $\alpha \mathrm{GD}$ ), and polyoxyethylene(10) octylphenyl ether (Triton X-100) were purchased from Fujifilm Wako Pure Chemical Corp. Human serum albumin (HSA) was purchased from the Japan Blood Products Organization. Avidin (Avi) was purchased from Calzyme Laboratories, Inc. Concanavalin A (ConA) from Canavalia ensiformis (Jack-bean) was purchased from J-Oil Mills, Inc. The magnetite $\left(\mathrm{Fe}_{3} \mathrm{O}_{4}\right)$ nanoparticle (MNP) (EMG607, ca. $10 \mathrm{~nm}$ diameter covered with cationic surfactant) was purchased from Ferrotec Corp. Biotinylated catalase (bCat) and biotinylated HSA (bHSA) were prepared according to a procedure reported earlier. ${ }^{26}$ Fluoresceinlabeled Cat (FCat) and $\alpha \mathrm{GD}(\mathrm{F} \alpha \mathrm{GD})$ were prepared by general procedure using fluorescein isothiocyanate (FITC; Sigma-Aldrich Co. LLC). Cyanine dye-labeled ConA (CyConA) and HRP (CyHRP) were prepared using a general procedure with cyanine5.5 NHS 
ester (Cy5.5; Lumiprobe Corp.). Citrated Au nanoparticles (AuNP, ca. $40 \mathrm{~nm}$ diameter) were synthesized as described in an earlier report. ${ }^{54}$ Deionized water (18.2 MQ $\mathrm{cm}$ ) was prepared using a water purification system (Elix UV and Milli Q Reference; Millipore Corp.). UV-vis absorption spectra were measured using a UV/Vis spectrophotometer (8453; Agilent Technologies Inc. or V-650; Jasco Corp.). Fluorescence emission spectra were recorded using a spectrofluorometer (FP-8300; Jasco Corp.).

\section{Template synthesis of precursor PLA/HSA/MNP(PLA/HSA $)_{5}$ PLA/ PLG/Avi microtubes (Avi MTs)}

The precursor Avi MTs were synthesized according to our earlier reported procedure using a track-etched polycarbonate (PC) membrane (isopore membrane, $25 \mathrm{~mm}$ diameter, $1.2 \mu \mathrm{m}$ pore-diameter, $4.94 \times 10^{7}$ pores per piece; Millipore Corp. $)^{26,37}$ with some modifications. The PC membrane was set in a stainless steel syringe holder $(25 \mathrm{~mm}$ diameter; Advantec Toyo Kaisha, Ltd). First, the sodium phosphate buffer (PB) solution (pH 7.2, $10 \mathrm{mM},+0.1 \mathrm{M} \mathrm{NaCl}, 10 \mathrm{~mL})$ of PLA $\left(1 \mathrm{mg} \mathrm{mL}^{-1}\right)$ was filtered through the membrane $\left(15 \mathrm{~mL} \mathrm{~h}^{-1}\right)$ using a syringe pump (PHD-2000; Harvard Apparatus). The excessively absorbed PLA was rinsed by water filtration $\left(12 \mathrm{~mL}, 60 \mathrm{~mL} \mathrm{~h}^{-1}\right)$. The membrane was dried under vacuum for $10 \mathrm{~min}$. Second, the PB solution ( $\mathrm{pH} 7.2,10 \mathrm{mM}, 10 \mathrm{~mL})$ of HSA $\left(2 \mathrm{mg} \mathrm{mL}^{-1}\right)$ was passed through $\left(30 \mathrm{~mL} \mathrm{~h}^{-1}\right)$. After washing by water filtration $\left(12 \mathrm{~mL}, 60 \mathrm{~mL} \mathrm{~h}^{-1}\right)$, the membrane was dried in vacuo for $10 \mathrm{~min}$. Third, a lid of the syringe holder was removed and the aqueous solution $(10 \mathrm{~mL})$ of MNP ( $\left.1 \mathrm{mg} \mathrm{mL}^{-1}\right)$ was dropped evenly onto the PC membrane with suction from the opposite side. After closing the lid and rinsing by water filtration $\left(12 \mathrm{~mL}, 60 \mathrm{~mL} \mathrm{~h}^{-1}\right)$, the pale-brown membrane was dried under vacuum for $10 \mathrm{~min}$. Subsequently, the pressure infiltrations of PLA and HSA described above were repeated in turn for 5.5 cycles to deposit the fourth to fourteenth layers. Then the PLG layer was made onto the pore wall using PB solution ( $\mathrm{pH} 7.2,10 \mathrm{mM}, 10 \mathrm{~mL})$ of PLG $\left(1 \mathrm{mg} \mathrm{mL} \mathrm{mL}^{-1}\right)$

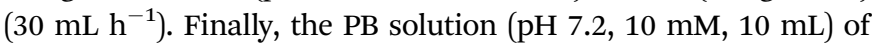
Avi $\left(2 \mathrm{mg} \mathrm{mL}^{-1}\right)$ was passed through $\left(15 \mathrm{~mL} \mathrm{~h}^{-1}\right)$ two times to create the Avi innermost layer. The PC membrane was washed by water dropping $(10 \mathrm{~mL})$ onto the membrane with suction from the opposite side and drying in vacuo for $30 \mathrm{~min}$.

The surface of the PC membrane including multilayered tubules was wiped using a cotton swab with deionized water and was immersed into a DMF solution using tweezers to dissolve the PC flame. The precipitated MTs were washed twice with DMF and 1,4-dioxane, and were freeze-dried in vacuo, yielding the lyophilized PLA/HSA/MNP(PLA/HSA) ${ }_{5} \mathrm{PLA} / \mathrm{PLG} / \mathrm{Avi}$ MTs (Avi MTs) as pale-yellow powder.

\section{Synthesis of ConA-covered Cat MTs (ConA/Cat MTs)}

The Avi MTs (ca. $8.23 \times 10^{6}$ tubes, one-sixth of the powder prepared using one PC membrane) were dispersed in deionized water $(3.41 \mathrm{~mL})$ using an ultrasonic cleaner for $1 \mathrm{~min}$. This aqueous dispersion was divided into two. After the $20 \times$ phosphate-buffered saline (PBS) solution ( $\mathrm{pH} 7.4,0.1 \mathrm{~mL}$ ) and 9\% $\mathrm{NaCl}$ solution $(195 \mu \mathrm{L})$ were added to each dispersion, the mixture was incubated for $30 \mathrm{~min}$ at $25{ }^{\circ} \mathrm{C}$. Then, the PB solution ( $\mathrm{pH} 7.0,10 \mathrm{mM}, 1.3 \mu \mathrm{L})$ of bCat $(26.2 \mu \mathrm{M})$ was injected into the dispersion. The resultant mixture (ca. $2.06 \times$ $10^{6}$ tubes per $\mathrm{mL},[\mathrm{bCat}]=17 \mathrm{nM},[\mathrm{bCat}] /[$ Avi $]=1.8(\mathrm{~mol} / \mathrm{mol})$, PBS $+150 \mathrm{mM} \mathrm{NaCl}, 2 \mathrm{~mL}$ ) was incubated for $3 \mathrm{~h}$ at $25{ }^{\circ} \mathrm{C}$ under darkness. After centrifugation $(500 \times g, 3 \mathrm{~min})$, the supernatant, including unbound bCat, was discarded. The precipitated MTs, PLA/HSA/MNP(PLA/HSA) ${ }_{5}$ PLA/PLG/Avi/bCat MTs (Cat MTs), were resuspended in 4-(2-hydroxyethyl)-1-piperazineethanesulfonic acid (HEPES) buffer solution (pH 6.8, $10 \mathrm{mM},+1 \mathrm{mM} \mathrm{CaCl}_{2},+1 \mathrm{mM}$ $\left.\mathrm{MnCl}_{2}, 2 \mathrm{~mL}\right)$ and were centrifuged again $(500 \times g, 3 \mathrm{~min})$. After removing the supernatant, HEPES solution was added to adjust the volume of $0.35 \mathrm{~mL}$. Subsequently, the HEPES solution of ConA (1 $\mathrm{mg} \mathrm{mL} \mathrm{mL}^{-1}, 0.15 \mathrm{~mL}$ ) was added. The resultant mixture was incubated for $30 \mathrm{~min}$ at $25{ }^{\circ} \mathrm{C}$. Then, after the dispersion was centrifuged $(500 \times g, 3 \mathrm{~min})$, the supernatant was discarded, followed by addition of HEPES solution $(2 \mathrm{~mL})$. By repeating this washing twice, we obtained the HEPES solution (2 mL) of ConA/ PLA/HSA/MNP(PLA/HSA) ${ }_{5}$ PLA/PLG/Avi/bCat MTs (ConA/Cat MTs). Using the same procedure, ConA/PLA/HSA/MNP(PLA/HSA) 5 PLA/ PLG MTs (ConA/PLG MTs) and HSA/PLA/HSA/MNP(PLA/HSA) PLA/PLG/Avi/bCat MTs (HSA/Cat MTs) were also prepared.

\section{Coverage rate estimation with ConA}

The coverage rate of the outer surface of Cat MTs with ConA was estimated using a fluorescent CyConA. The Cat MTs were prepared in the manner described above $\left(\mathrm{ca} .2 .06 \times 10^{6}\right.$ tubes per $\mathrm{mL},[$ bCat $]=17 \mathrm{nM},[$ bCat $] /[$ Avi $]=1.8(\mathrm{~mol} / \mathrm{mol})$, PBS +150 $\mathrm{mM} \mathrm{NaCl}, 2 \mathrm{~mL}$ ). The dispersion was centrifuged $(500 \times g, 3 \mathrm{~min})$ to remove the supernatant including free bCat. The precipitated Cat MTs were suspended in PB solution $(\mathrm{pH} 7.0,10 \mathrm{mM}, 2 \mathrm{~mL})$ and were centrifuged again $(500 \times g$, $3 \mathrm{~min}$ ). After removing the supernatant, PB solution was added to adjust the volume of $0.9 \mathrm{~mL}$. Subsequently, the PB solution of CyConA $(0.4 \mu \mathrm{M}, 0.1 \mathrm{~mL})$ was added and the mixture was incubated for $30 \mathrm{~min}$ at $25{ }^{\circ} \mathrm{C}$. The dispersion of the CyConA/ Cat MTs was centrifuged $(4000 \times g, 10 \mathrm{~min})$. Then the fluorescence spectrum of the supernatant $(0.8 \mathrm{~mL})$ was measured $\left(\lambda_{\mathrm{ex}}\right.$, $684 \mathrm{~nm} / \lambda_{\mathrm{em}}, 710 \mathrm{~nm}$ ) to ascertain the concentration of the unbound free CyConA. An identically treated control CyConA sample without MT was prepared; its fluorescence intensity was regarded as a $100 \%$ CyConA concentration. CyConA/FCat MTs were also prepared using the same synthetic procedure for CLSM observations.

\section{E. coli capture by ConA/Cat MTs}

The green fluorescent protein (GFP) secreted E. coli (F-E. coli) was prepared using an HB101 (K-12) competent cell and pGLO ${ }^{\mathrm{TM}}$ Bacterial Transformation Kit (Bio-Rad Laboratories Inc.). The HEPES dispersion ( $\mathrm{pH}$ 6.8, $10 \mathrm{mM},+1 \mathrm{mM} \mathrm{CaCl}_{2},+1 \mathrm{mM} \mathrm{MnCl}_{2}$, $2 \mathrm{~mL}$ ) of ConA/Cat MTs ( ca. $2.06 \times 10^{6}$ tubes per mL), prepared as described above, was divided by four into $2 \mathrm{~mL}$-volume plastic tubes. Using a neodymium (Nd)-magnet (468 mT, $30 \mathrm{~mm}$ diameter $\times 15 \mathrm{~mm})$, the MTs were collected at the bottom and the supernatant was removed. The obtained ConA/Cat MTs were redispersed into HEPES solution $(0.8 \mathrm{~mL})$ containing $\mathrm{H}_{2} \mathrm{O}_{2}$ (2.5 wt\%) and Triton X-100 (0.125 wt\%) to promote self-propulsion 
of the tubes. Thereafter, the HEPES suspension $(0.2 \mathrm{~mL})$ of F-E. coli $\left(\mathrm{OD}_{600}=0.05,2.5 \times 10^{7}\right.$ cells per $\left.\mathrm{mL}\right)$ was added slowly. The resultant mixture $\left(\mathrm{ca} .1 .03 \times 10^{6}\right.$ tubes per $\mathrm{mL},[\mathrm{F}-E$. coli $]=5.0 \times$ $10^{6}$ cells per $\mathrm{mL},\left[\mathrm{H}_{2} \mathrm{O}_{2}\right]=2 \mathrm{wt} \%$, [Triton $\left.\mathrm{X}-100\right]=0.1 \mathrm{wt} \%, 1 \mathrm{~mL}$ ) was left for $15 \mathrm{~min}$ without vibration at $25{ }^{\circ} \mathrm{C}$. By exposure to a magnetic field using a Nd-magnet, the F-E. coli bound ConA/Cat MTs were collected at the bottom. The supernatant was transferred to other plastic tubes. This supernatant was centrifuged $(4000 \times g, 10 \mathrm{~min})$. The precipitated F- $E$. coli was redispersed in HEPES solution $(1 \mathrm{~mL})$. Fluorescence measurement of this dispersion $\left(\lambda_{\mathrm{ex}}, 395 \mathrm{~nm} / \lambda_{\mathrm{em}}\right.$, $508 \mathrm{~nm}$ ) was used to estimate the concentration of the unbound free F- $E$. coli. An identically treated control sample without MT was prepared. Its fluorescence intensity was regarded as a $100 \% \mathrm{~F}-E$. coli concentration. The same experiments were conducted using the ConA/PLG MTs and HSA/Cat MTs.

\section{Enzyme reaction measurements of $\alpha \mathrm{GD} /$ Cat MTs}

Synthesis of $\alpha \mathrm{GD} / \mathrm{Cat}$ MTs was described in ESI. $\dagger$ The PB dispersion (pH 7.0, $10 \mathrm{mM}, 0.5 \mathrm{~mL}$ ) of $\alpha \mathrm{GD} /$ Cat MTs (ca. $1.65 \times 10^{7}$ tubes per $\mathrm{mL}$ ) was diluted to $1.37 \mathrm{~mL}$ and put it in a 10-mm path length optical quartz cuvette. After the $\mathrm{PB}$ solution ( $\mathrm{pH} 7.0,10 \mathrm{mM})$ of Triton X-100 (5 wt\%, $30 \mu \mathrm{L})$ was added, the mixture was incubated for $10 \mathrm{~min}$ at $25{ }^{\circ} \mathrm{C}$. Then NMP solution of MUGlc $(5 \mathrm{mM}, 15 \mu \mathrm{L})$ was injected into the dispersion, followed by addition of $\mathrm{H}_{2} \mathrm{O}_{2}$ solution (35.6 wt\%, $85 \mu \mathrm{L})$ immediately to the cuvette $\left(c a .5 .5 \times 10^{6}\right.$ tubes per $\mathrm{mL}$, $\left[\mathrm{H}_{2} \mathrm{O}_{2}\right]=2 \mathrm{wt} \%$, [Triton X-100] $=0.1 \mathrm{wt} \%$, [MUGlc] $\left.=50 \mu \mathrm{M}\right)$. An increase in fluorescence of the product 4-methylumbelliferone (MU) $\left(\lambda_{\mathrm{ex}}, 370 \mathrm{~nm} / \lambda_{\mathrm{em}}, 447 \mathrm{~nm}\right)$ was monitored at $25{ }^{\circ} \mathrm{C}$ for $50 \mathrm{~min}$. The MU concentration was ascertained from the fluorescence intensity. The appearance of emission was observed visually under irradiation of $365 \mathrm{~nm}$ UV light. Identical experiments were conducted with non-swimming $\alpha \mathrm{GD} / \mathrm{PLG}$ MTs with stirring (300 rpm) and without stirring.

\section{Enzyme reaction measurements of HRP/Cat MTs}

Synthesis of HRP/Cat MTs was described in ESI. $\dagger$ The PB dispersion (pH 7.0, $10 \mathrm{mM}, 0.5 \mathrm{~mL}$ ) of HRP/Cat MTs (ca. $1.65 \times$ $10^{7}$ tubes per $\mathrm{mL}$ ) was diluted to $1.0 \mathrm{~mL}$ and put it in a $5 \mathrm{~mL}$ volume glass bottle. Freshly prepared PB solution (pH 7.0, $10 \mathrm{mM}$, $0.5 \mathrm{~mL}$ ) including $\mathrm{H}_{2} \mathrm{O}_{2}$ (3 wt $\left.\%\right)$, Triton $\mathrm{X}-100(0.15 \mathrm{wt} \%)$, and substrate (o-phenylenediamine (OPD) or o-dianisidine dihydrochloride (OD), $225 \mu \mathrm{M}$ ) was added to the solution. Then the mixture was left for $20 \mathrm{~min}$ at $25{ }^{\circ} \mathrm{C}\left(5.5 \times 10^{6}\right.$ tubes per $\mathrm{mL}$, $\left[\mathrm{H}_{2} \mathrm{O}_{2}\right]=2 \mathrm{wt} \%$, [Triton X-100] $=0.1 \mathrm{wt} \%$, [substrate] $\left.=150 \mu \mathrm{M}\right)$. By exposure of a Nd-magnet, the HRP/Cat MTs were collected. The supernatant was transferred to a $10 \mathrm{~mm}$ path length optical quartz cuvette to measure the UV-vis absorption spectrum of the oxidized product [2,3-diaminophenazine (DAP; $\lambda_{\max }, 417 \mathrm{~nm}$ ) or bisazobiphenyl derivative (BAB; $\lambda_{\max }, 455 \mathrm{~nm}$ )]. Identical experiments were also conducted using non-swimming HRP/ HSA MTs with stirring (300 rpm) and without stirring.

\section{Optical microscopy observations of swimming MTs}

Typically, the HEPES dispersion ( $\mathrm{pH} 6.8,10 \mathrm{mM}, \mathrm{ca} .1 .06 \times 10^{6}-$ $4.12 \times 10^{6}$ tubes per $\mathrm{mL},\left[\mathrm{H}_{2} \mathrm{O}_{2}\right]=2 \mathrm{wt} \%$, [Triton $\left.\mathrm{X}-100\right]=0.1 \mathrm{wt} \%$ ) or $\mathrm{PB}$ dispersion $\left(\mathrm{pH} 7.0,10 \mathrm{mM}\right.$, ca. $1.06 \times 10^{6}-4.12 \times 10^{6}$ tubes per $\mathrm{mL},\left[\mathrm{H}_{2} \mathrm{O}_{2}\right]=2 \mathrm{wt} \%$, [Triton X-100] $=0.1 \mathrm{wt} \%$ ) of swimming MTs were prepared in a 24-well glass bottom microplate (Iwaki EZVIEW Culture Plate LB; AGC Techno Glass., Co., Ltd). The moving behavior was observed using a research inverted microscope (IX73; Olympus Corp.) under bright field mode equipped with a digital high-speed camera (HAS-220; Detect Corp.) at 200 frames per s. Editing of the movies and determination of the tube velocity were performed using an image processing program (Image J; NIH).

\section{Optical microscopy observations of swimming AuNP/Cat MTs under light irradiation}

Synthesis of AuNP/Cat MTs was described in ESI. $\dagger$ Movements of the AuNP/Cat MT were observed under bright field mode with light irradiation using a $\mathrm{Hg}$ lamp through a fluorescence mirror unit (U-FGW, Ex, 530-550 nm/Em, $575 \mathrm{~nm}$ ) at room temperature. The irradiation light intensity was regulated using ND filters $\left(0-193 \mathrm{~mW} \mathrm{~cm} \mathrm{~cm}^{-2}\right)$. The solution temperature was measured using a digital thermometer (TF-2100; As One Corp.).

\section{Author contributions}

T. K. designed and initiated this study. All the authors conducted experiments and analysed the data. M. U., N. S., K. M., and T. K. drafted the manuscript.

\section{Conflicts of interest}

There are no conflicts to declare.

\section{Acknowledgements}

This work was supported by Grants-in-Aid for Scientific Research (B) (No. 18H01833 and No. 21H01767) from JSPS.

\section{References}

1 Y. Mei, G. Huang, A. A. Solovev, E. B. Ureña, I. Mönch, F. Ding, T. Reindl, R. K. Y. Fu, P. K. Chu and O. G. Schmidt, Adv. Mater., 2008, 20, 4085-4090.

2 W. Gao, S. Sattayasamitsathit, J. Orozco and J. Wang, J. Am. Chem. Soc., 2011, 133, 11862-11864.

3 Y. Mei, A. A. Solovev, S. Sanchez and O. G. Schmidt, Chem. Soc. Rev., 2011, 40, 2109-2119.

$4 \mathrm{H}$. Wang and M. Pumera, Chem. Rev., 2015, 115, 8704-8735.

5 Z. Wu, X. Lin, T. Si and Q. He, Small, 2016, 12, 3080-3093.

6 B. Xu, B. Zhang, L. Wang, G. Huang and Y. Mei, Adv. Funct. Mater., 2018, 28, 1705872.

7 T. Komatsu, Chem. Lett., 2020, 49, 1245-1255.

8 H. Wang, J. G. S. Moo and M. Pumera, ACS Nano, 2016, 10, 5041-5050.

9 J. Li, S. Thamphiwatana, W. Liu, B. Esteban-Fernández de Ávila, P. Angsantikul, E. Sandraz, J. Wang, T. Xu, F. Soto, 
V. Ramez, X. Wang, W. Gao, L. Zhang and J. Wang, ACS Nano, 2016, 10, 9536-9542.

10 B. Esteban-Fernández de Ávila, P. Angsantikul, X. Li, W. Gao, L. Zhang and J. Wang, Adv. Funct. Mater., 2018, 28, 1705640.

11 Y. Yoshizumi and H. Suzuki, ACS Appl. Mater. Interfaces, 2017, 9, 21355-21361.

12 Y. Nakai, N. Sugai, H. Kusano, Y. Morita and T. Komatsu, ACS Appl. Nano Mater., 2019, 2, 4891-4899.

13 L. Soler, V. Magdanz, V. M. Fomin, S. Sanchez and O. G. Schmidt, ACS Nano, 2013, 11, 9611-9620.

14 W. Gao and J. Wang, ACS Nano, 2014, 8, 3170-3180.

15 A. A. Solovev, A. Sanchez, M. Pumera, Y. F. Mei and O. G. Schmidt, Adv. Funct. Mater., 2010, 20, 2430-2435.

16 S. Campuzano, J. Orozco, D. Kagan, M. Guix, W. Gao, S. Sattayasamitsathit, J. C. Claussen, A. Merkoçi and J. Wang, Nano Lett., 2012, 12, 396-401.

17 J. Orozco, A. Cortés, G. Cheng, S. Sattayasamitsathit, W. Gao, X. Feng, Y. Shen and J. Wang, J. Am. Chem. Soc., 2013, 135, 5336-5339.

18 X. Bing, X. Zhang, J. Li, D. H. L. Ng, W. Yang and J. Yang, J. Mater. Chem. A, 2020, 8, 2809-2819.

19 X. Yu, Y. Li, J. Wu and H. Ju, Anal. Chem., 2014, 86, 4501-4507.

20 C. C. Mayorga-Martinez and M. Pumera, Adv. Funct. Mater., 2020, 30, 1906449.

21 Á. Molinero-Fernández, M. Á. López and A. Escarpa, Anal. Chem., 2020, 92, 5048-5054.

22 S. Sanchez, A. A. Solovev, Y. Mei and O. G. Schmidt, J. Am. Chem. Soc., 2010, 132, 13144-13145.

23 J. Orozco, V. García-Gradilla, M. D’Agostino, W. Gao, A. Cortés and J. Wang, ACS Nano, 2013, 7, 818-824.

24 Z. Wu, W. Lin, X. Zou, J. Sun and Q. He, ACS Appl. Mater. Interfaces, 2015, 7, 250-255.

25 S. Fu, X. Zhang, Y. Xie, J. Wu and H. Ju, Nanoscale, 2017, 9, 9026-9033.

26 N. Sugai, Y. Nakai, Y. Morita and T. Komatsu, ACS Appl. Nano Mater., 2018, 2, 3080-3085.

27 K. Villa and M. Pumera, Chem. Soc. Rev., 2019, 48, 4966-4978.

28 F. Mou, Y. Li, C. Chen, W. Li, Y. Yin, H. Ma and J. Guan, Small, 2015, 11, 2564-2570.

29 K. Villa, C. L. M. Palenzuela, Z. Sofer, S. Matějková and M. Pumera, ACS Nano, 2018, 12, 12482-12491.

30 Z. Wu, T. Si, W. Gao, X. Lin, J. Wang and Q. He, Small, 2016, 12, 577-582.

31 W. Wang, Z. Wu, X. Lin, T. Si and Q. He, J. Am. Chem. Soc., 2019, 141, 6601-6608.

32 J. L. Perry, C. R. Martin and J. D. Stewart, Chem. - Eur. J., 2011, 17, 6296-6302.

33 T. Komatsu, Nanoscale, 2012, 4, 1910-1918.

34 S. Zhang, F. Xia, S. Demoustier-Champagne and A. M. Jonas, Nanoscale, 2020, 13, 7471-7497.

35 J. Li, Y. Jia, W. Dong, X. Feng, J. Fei and J. Li, Nano Lett., 2014, 14, 6160-6164.
36 B. Aor, I. Khan, K. Glinel, A. M. Jonas, S. DemoustierChampagne and M. C. Durrieu, ACS Appl. Bio Mater., 2020, 3, 1520-1532.

37 X. Qu and T. Komatsu, ACS Nano, 2010, 4, 563-573.

38 T. Komatsu, X. Qu, H. Ihara, M. Fujihara, H. Azuma and H. Ikeda, J. Am. Chem. Soc., 2011, 133, 3246-3248.

39 S. Yuge, M. Akiyama, M. Ishii, H. Namkoong, K. Yagi, Y. Nakai, R. Adachi and T. Komatsu, Chem. Lett., 2017, 46, 95-97.

40 S. Yuge, M. Akiyama and T. Komatsu, Chem. Commun., 2014, 50, 9640-9643.

41 R. Adachi, M. Akiyama, Y. Morita and T. Komatsu, Chem. Asian J., 2018, 13, 2796-2799.

42 O. Livnah, E. A. Bayer, M. Wilchek and J. L. Sussman, Proc. Natl. Acad. Sci. U. S. A., 1993, 90, 5076-5080.

43 J. H. Naismith and R. A. Field, J. Biol. Chem., 1996, 271, 972-976.

44 Z. Shen, M. Huang, C. Xiao, Y. Zhang, X. Zeng and P. G. Wang, Anal. Chem., 2007, 79, 2312-2329.

45 S. T. Dubas and J. B. Schlenoff, Langmuir, 2001, 17, 7725-7727.

46 M. D. Miller and M. L. Bruening, Chem. Mater., 2005, 17, 5375-5381.

47 S. Chiba, Biosci., Biotechnol., Biochem., 1997, 61, 1233-1239.

48 T. Komatsu, H. Terada and N. Kobayashi, Chem. - Eur. J., 2011, 17, 1849-1854.

49 J. N. Rondríguez-López, M. A. Gilabert, J. Tudela, R. N. F. Thorneley and F. García-Cánovas, Biochemistry, 2000, 39, 13201-13209.

50 S. Fornera and P. Walde, Anal. Biochem., 2010, 407, 293-295.

51 A. Claiborne and I. Fridovich, Biochemistry, 1979, 18, 2324-2329.

52 L. C. Kennedy, L. R. Bickford, N. A. Lewinski, A. J. Coughlin, Y. Hu, E. S. Day, J. L. West and R. A. Drezek, Small, 2011, 7, 169-183.

53 Q. Feng, B. Tang, Q. Wei, D. Hou, S. Bi and A. Wei, Int. J. Mol. Sci., 2012, 13, 12734-12746.

54 S. Goto, Y. Amano, M. Akiyama, C. Böttcher and T. Komatsu, Langmuir, 2013, 29, 14923-14930.

55 T. J. Norman, C. D. Grant, D. Magana, J. Z. Zhang, J. Liu, D. Cao, F. Bridges and A. Van Buuren, J. Phys. Chem. B, 2002, 106, 7005-7012.

56 B. Szalay, E. Tátrai, G. Nyíro, T. Vezér and G. Dura, J. Appl. Toxicol., 2012, 32, 446-453.

57 T. Hamasaki, T. Kashiwagi, T. Imada, N. Nakamichi, S. Aramaki, K. Toh, S. Morisawa, H. Shimakoshi, Y. Hisaeda and S. Shirahata, Langmuir, 2008, 24, 7354-7364. 58 T. Patiño, X. Arqué, R. Mestre, L. Palacios and S. Sánchez, Acc. Chem. Res., 2018, 51, 2662-2671.

59 Y. Zhang, H. Zhou, W. Qiu, Y. Zhou, G. Huang, Y. Mei and A. A. Solovev, Chem. Commun., 2018, 54, 5692-5695.

60 N. Sugai, Y. Morita and T. Komatsu, Chem. - Asian J., 2019, 14, 2953-2957. 